\title{
Six-flow operations for catalyst development in Fischer-Tropsch synthesis: Bridging the gap between high-throughput experimentation and extensive product evaluation
}

\author{
Sina Sartipi, a) Harrie Jansma, Duco Bosma, Bart Boshuizen, Michiel Makkee, \\ Jorge Gascon, ${ }^{\text {a) }}$ and Freek Kapteijn \\ Department of Chemical Engineering, Catalysis Engineering, Delft University of Technology, \\ Julianalaan 136, 2628 BL Delft, The Netherlands
}

(Received 6 September 2013; accepted 13 November 2013; published online 4 December 2013)

\begin{abstract}
Design and operation of a "six-flow fixed-bed microreactor" setup for Fischer-Tropsch synthesis (FTS) is described. The unit consists of feed and mixing, flow division, reaction, separation, and analysis sections. The reactor system is made of five heating blocks with individual temperature controllers, assuring an identical isothermal zone of at least $10 \mathrm{~cm}$ along six fixed-bed microreactor inserts ( $4 \mathrm{~mm}$ inner diameter). Such a lab-scale setup allows running six experiments in parallel, under equal feed composition, reaction temperature, and conditions of separation and analysis equipment. It permits separate collection of wax and liquid samples (from each flow line), allowing operation with high productivities of $\mathrm{C} 5+$ hydrocarbons. The latter is crucial for a complete understanding of FTS product compositions and will represent an advantage over high-throughput setups with more than ten flows where such instrumental considerations lead to elevated equipment volume, cost, and operation complexity. The identical performance (of the six flows) under similar reaction conditions was assured by testing a same catalyst batch, loaded in all microreactors. () 2013 AIP Publishing LLC. [http://dx.doi.org/10.1063/1.4834895]
\end{abstract}

\section{INTRODUCTION}

The key principle of high-throughput experimentation is parallelization, ${ }^{1-3}$ an approach to run several tests simultaneously rather than carrying them out one after another. ${ }^{4}$ This is a valuable tool to conduct cost efficient research and development. While parallelization of experiments increases the research load without subsequently increasing the development time, small scale testing results in a reduction of materials and feed, ultimately decreasing the total cost per experiment. ${ }^{5}$

When it comes to catalyst development, much care has to be taken when parallelizing kinetic experiments to avoid missing valuable information. Increasing catalyst screening throughput may lead to partial or even wrong conclusions, especially in case of complex reactions such as Fischer-Tropsch synthesis (FTS).

FTS is an alternative process for the sustainable production of key chemical building blocks from non-petroleumbased resources such as natural gas, coal, or biomass. The scientific community has devoted a great deal of efforts to FTS-related technologies during the last few decades due to the increasing price of crude oil, the rapid increase of natural gas reserves, and environmental concerns. ${ }^{6}$

When liquid fuels such as diesel are aimed, FTS process conditions and catalysts are designed to maximize the socalled chain growth probability $(\alpha)$, i.e., to increase the production of liquid (C5-C20) and wax (C21+) fractions. Long chain hydrocarbons are further hydrocracked to narrow the product distribution to the desired hydrocarbon cut. ${ }^{7,8}$

\footnotetext{
${ }^{a)}$ Authors to whom correspondence should be addressed. Electronic addresses: S.Sartipi@tudelft.nl and J.Gascon@tudelft.nl. Fax: +31 15 2785006. Tel.: +31 152786733 .
}

Since its discovery (almost one century ago), many studies dealing with FTS catalyst development have been published. Nevertheless, hazardous nature of the reactants $\left(\mathrm{H}_{2}\right.$ and $\mathrm{CO}$ ) and on the other hand, complexity of the products (hydrocarbons in a wide range of boiling points, oxygenates, etc.) has been an obstacle for relevant catalyst performance evaluations in many occasions. In this respect, advances in laboratory instrumentation, operation atomization, data acquisition and treatment, etc., in the last couple of decades have allowed meeting the high demand for accurate and efficient catalyst performance evaluation methods.

In an early course of FTS reaction, the initial chemical and structural properties of a freshly activated catalyst change, resulting in evolution of activity and product selectivity as the reaction proceeds. Catalyst stabilization under reaction conditions may take more than 100 h. $^{9}$ On the other hand, long chain hydrocarbons formed over the FTS active phase have to fill the catalyst porosity and liquid reactor effluents will wet the internal surface of the equipment. Depending on the setup volume, its stabilization period might be shorter than that of the catalyst. Yet, sufficient time is required in order to substitute (wash off) the products of a preceding reaction from the tubing and equipment's internal volume by the new effluents. Consequently, experiments related to FTS catalyst evaluation are time demanding and thus reaction parallelization is highly advantageous. We were among the first research groups that proposed the concept of such high-throughput experimentation, under realistic FTS process conditions. ${ }^{2,10-12}$ To date high-throughput FTS setups with up to 64 parallel reactors are reported and marketed. ${ }^{13}$

Although high-throughput experimental setups are very suitable for exploratory screening of catalysts, they are 
often limited to analysis of the gas phase products. ${ }^{14-16}$ Bringing the higher hydrocarbons to the gas phase is to some extent possible by diluting the reactor effluents. However, the separation of such mixture by an online gas chromatograph (GC) will become demanding due to significant differences in the hydrocarbons boiling points. In this contribution, the "sixflow fixed-bed microreactor Fischer-Tropsch synthesis" setup concept is introduced for lab scale catalyst performance assessments. The detailed equipment design and configuration is reported and linked to operation modes which lead to performing six parallel reactions with an extensive evaluation of the product spectrum. Furthermore, the accuracy of obtained data is assessed and discussed by screening the same catalyst batch in the six reactors (flows).

\section{SETUP CONFIGURATION}

The overall design of the lab-scale unit for FTS reaction is shown in Figure 1. This setup consists of the following sections: (1) feed and mixing, (2) flow division, (3) reaction, (4) separation, and (5) analysis. The detailed process flow scheme with respect to the above-mentioned five sections is presented in Figure 2 (for description of used symbols and acronyms, see Fig. 3).

\section{A. Feed and mixing/flow division}

In the feed and mixing section, flows of pure $\mathrm{N}_{2}, \mathrm{H}_{2}$, and $\mathrm{CO}$ are set by individual mass flow controllers (MFC 1, 2, and 3, respectively, Figure 2) after they are purified from possible traces of particular matter, $\mathrm{H}_{2} \mathrm{O}$, and $\mathrm{O}_{2}$ by a set of filters (1-3) and traps (OWT 1-3). Moreover, an additional supply line is implemented in this section. A fourth gas may be introduced to the setup by MFC 4 via this extra line for different purposes (e.g., an already prepared (model) mixture as

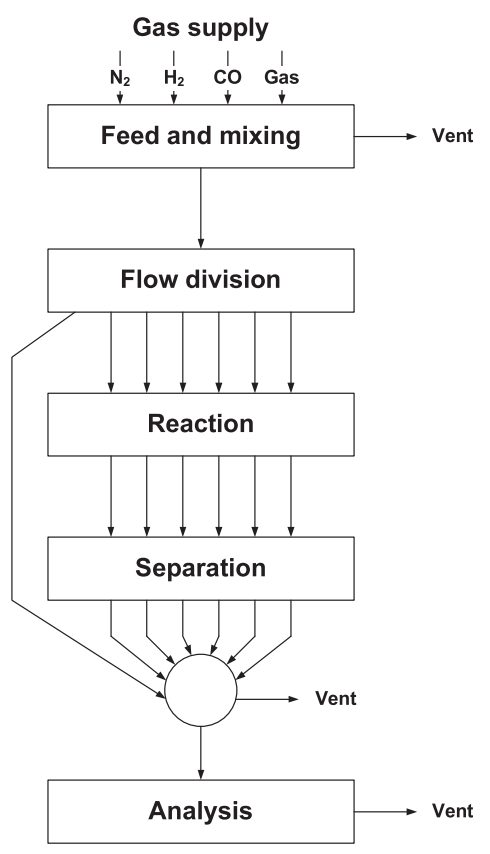

FIG. 1. Overall process flow scheme of the six-flow fixed-bed microreactor FTS setup. feed, He for leak detection, etc.). CO can react with metals such as $\mathrm{Fe}, \mathrm{Ni}$, and $\mathrm{Cr}$ at a high pressure to form highly toxic metal carbonyls. Therefore, the tubing material is either fused silica coated SS 304 or titanium where it is in contact with $\mathrm{CO}$ (at high pressures and/or temperatures). Furthermore, an electrical heater $(\mathrm{EH})$, operated at $473 \mathrm{~K}$, followed by a water cooling unit (WCU) is placed downstream of the CO mass flow controller to decompose the carbonyls that were possibly formed in the gas network.

By means of a set of three-way valves (TWV 1-3), flows of pure gases can be switched to a "reactor manifold" and thus mixed to produce the desired feed composition. In the flow division part, six flows are tapped from the reactor manifold, each connected to an individual mass flow controller (MFC 510, Figure 2). The excess flow mixture leaves the manifold via the backpressure controller BPC 2 and maintains a constant feed pressure for these mass flow controllers.

\section{B. Reaction}

The reaction section is surrounded by a large heating box (oven) which is shown in Figures 4(a) (marked with $\triangle$ ) and 4(b). The temperature of this oven is set at $448 \mathrm{~K}$ in order to prevent solidification of FTS products in tubing and other equipment. A "six-flow fixed-bed microreactor" (marked with $\square$ in Figure 4(b)) is located inside the oven with equal distances from the oven walls where heating elements are mounted. The reactor system consists of five heating sections (Figure 5(a)) with individual temperature controllers (Figure $\mathrm{S} 1$ in the supplementary material ${ }^{17}$ ). Six tubes fit in this reactor system, each including a glass-lined insert (4 mm inner diameter), where catalyst particles can be loaded (Figure 5(b)). The isothermal zone along the six fixed-bed microreactors (FBM 1-6) is identical and at least of $10 \mathrm{~cm}$ (Figure 5(c)).

As mentioned in Sec. II A, the feed flow rate to each FBM is set by an independent MFC. Additionally, a flow of $\mathrm{N}_{2}$ is introduced to the top-side part of each FBM (Figure 5(b)) by separate MFCs (11-16, Figure 2). The $\mathrm{N}_{2}$ stream flushes the gap between the outer and insert tubes and mixes with the reactors effluents downstream of the FBMs (Figure 2). In this way, $\mathrm{N}_{2}$ will not dilute the reaction environment. The pressure of the FBMs is set by separate back pressure controllers (BPC 3-8, Figure 2) which are located inside the oven and controlled from outside. A continuous flow of gas, assured by $\mathrm{N}_{2}$, results in a stable process pressure at high conversion levels and $\alpha$ values where most of the syngas feed is converted into liquid products. The $\mathrm{N}_{2}$ inert can also be used as an internal standard for the online gas analysis (see Sec. III A).

\section{Separation/analysis}

Due to differences in boiling points, FTS products may be in the form of either gas, liquid, or solid at ambient conditions. Separation of these fractions is of importance since: (i) heavy components may solidify in tubing and equipment at (possible) cold spots, and (ii) revealing the product composition asks for analysis strategies which may vary for different 


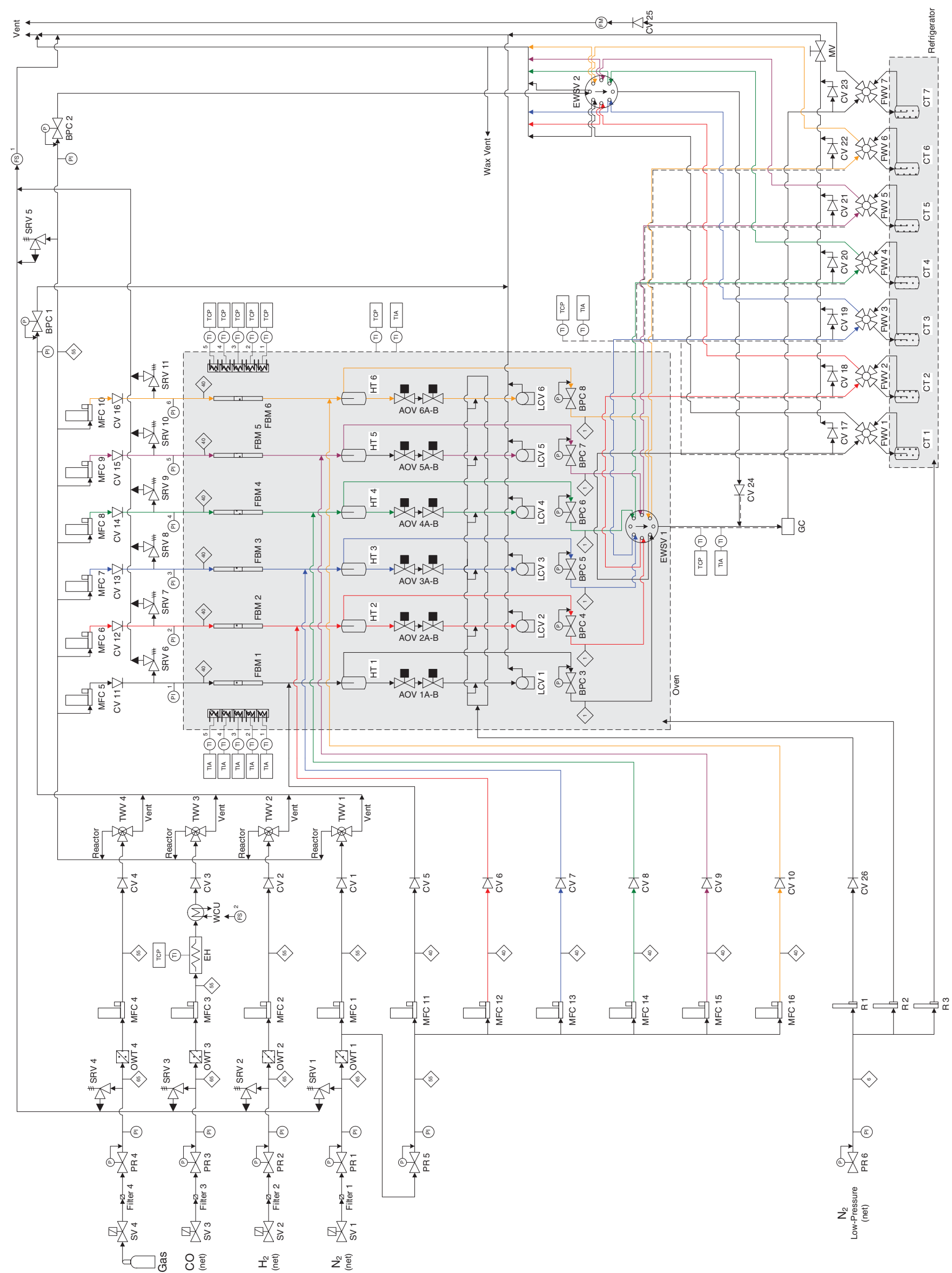

FIG. 2. Detailed process flow scheme of the six-flow fixed-bed microreactor FTS setup. Description of used symbols and acronyms is included in Figure 3 and Table $\mathrm{S} 1$ of the supplementary material. ${ }^{17}$ 


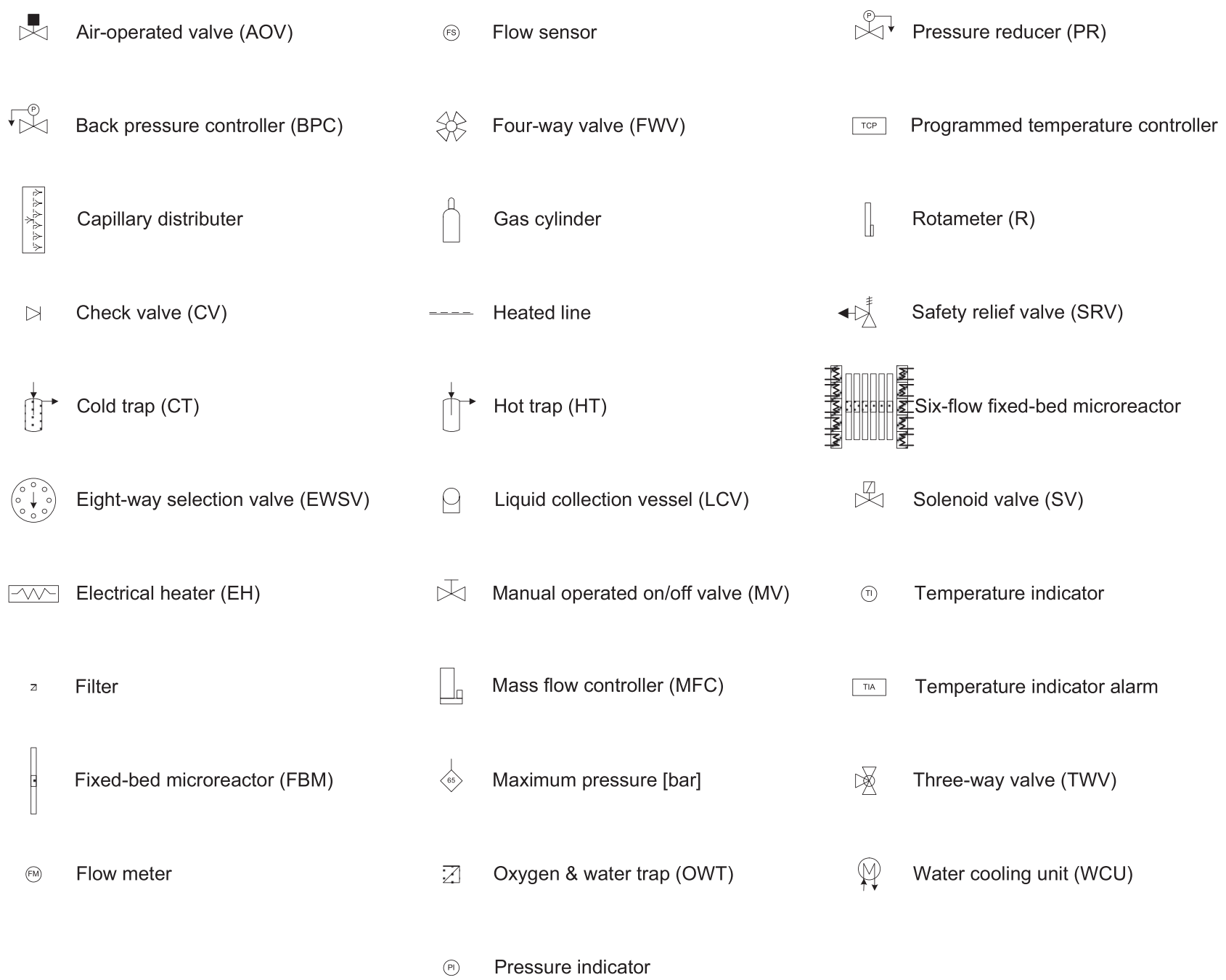

FIG. 3. Description of the symbols and acronyms used in Figure 2 (see Table $\mathrm{S} 1$ of the supplementary material ${ }^{17}$ for equipment models and more details).

hydrocarbon ranges. FTS wax which is mostly in the liquid phase at $448 \mathrm{~K}$ and typical reaction pressures $(\geq 10 \mathrm{bar})^{11}$ is collected by gas/liquid separators ("hot traps") located in the oven (HT 1-6, Figures 2 and 4(b)). HTs are regularly drained into liquid collection vessels (LCV 1-6) by assistance of two sets of air-operated on/off valves (AOV 1-6, set A and B). The system pressure allows discharging the wax, first from HTs into a piece of tube (that connects AOVs A to B) and, consequently, in LCVs through a subsequent sequence of opening and closure of the two sets of valves (see Figure S2 in the supplementary material ${ }^{17}$ for complete description). An inert environment is kept inside LCVs by $\sim 100 \mathrm{~cm}^{3} \mathrm{~min}^{-1}$ flow of $\mathrm{N}_{2}$ at atmospheric pressure.

After expansion to atmospheric pressure (by BPC 38 ), the products flow out from the oven via heated lines to a refrigerator where "cold traps" are located (CT 1-7, Figures 2 and 4(c)). Water and lighter hydrocarbons are separated from unreacted feed, gas phase hydrocarbons, and internal standard in CTs at $\sim 278 \mathrm{~K}$. To collect the liquids, a vial (marked with $\bigcirc$ in Figure 4(c)) can be inserted in CTs while they are bypassed by a set of four-way valves (FWV 1-6). (Note that precautions must be considered while re- moving the HTs and CTs since they may contain hazardous gases.)

Samples collected in LCVs and CTs may be analyzed offline, while the gas phase is analyzed by an online GC (see Sec. III). By means of two eight-way selection valves (EWSV), one located upstream of the CTs (in the oven, EWSV 1) and the other at their downstream (EWSV 2), two different analysis modes can be followed: (mode $i$ ) $\mathrm{C} 1-\mathrm{C} 20$ can be analyzed online, when the targeted flow (i.e., effluents of FBM 1-6) is selected by EWSV 1, before separation of the liquid fractions. This mode is preferred at low conversion levels and/or low $\alpha$ values, when a low production of liquid hydrocarbons is expected. (Mode ii) Once separated from the liquids, gas phase hydrocarbons can be analyzed online upon flow selection by EWSV 2. This mode is preferred at high conversion levels and high $\alpha$ values when a high concentration of heavy hydrocarbons and $\mathrm{H}_{2} \mathrm{O}$ may damage the GC columns. If a thorough product analysis is aimed for in the latter case, the online analysis should be supplemented by offline measurements of the collected samples (see Sec. III B).

A volumetric gas flow meter (FM) is installed downstream of the GC (sample loop) which can be used 

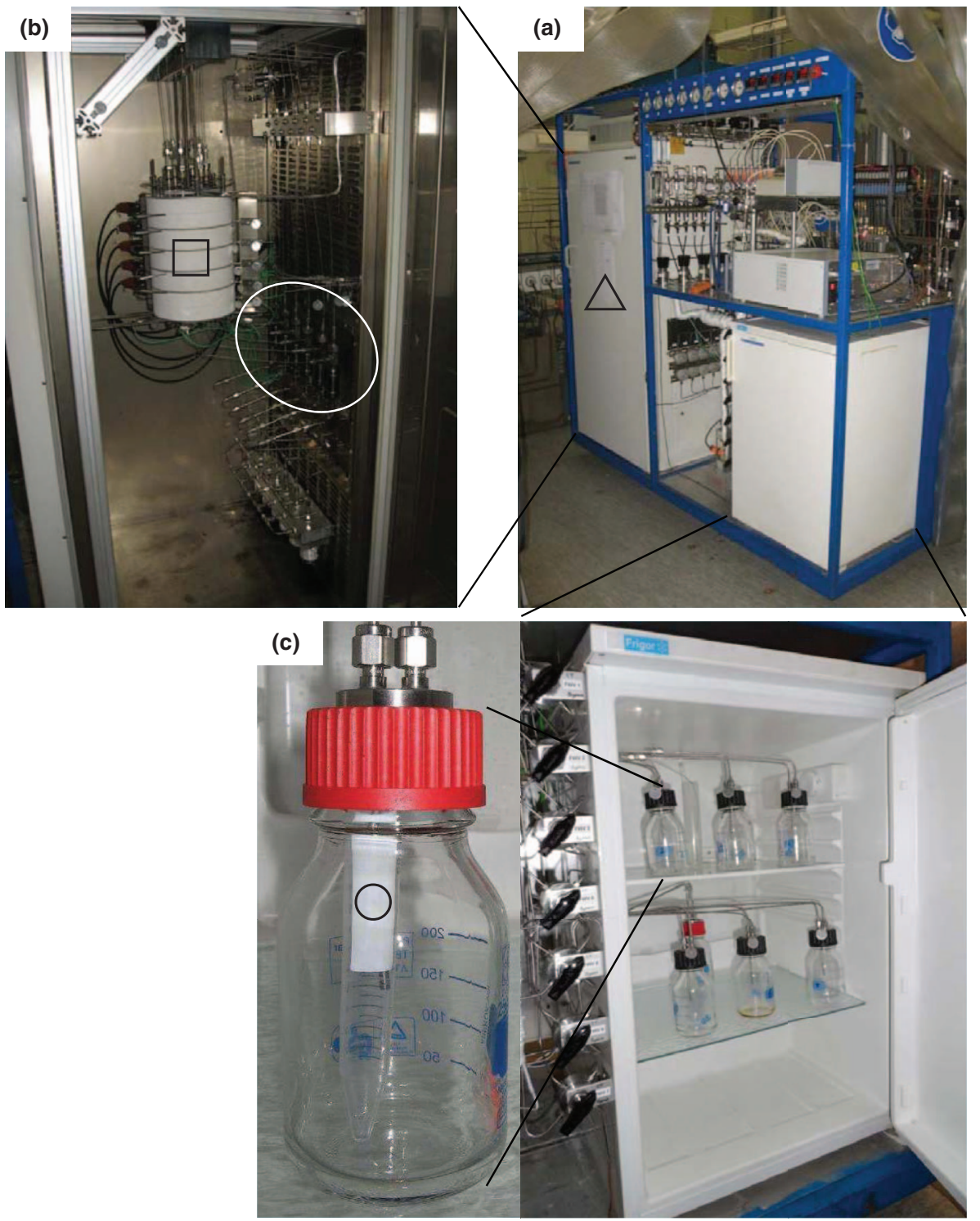

FIG. 4. Photographs of the six-flow fixed-bed microreactor FTS setup (a), the oven $(\Delta)$ where the five heated zones six-flow fixed-bed microreactor ( $\square$ ) is located at the center and hot traps beside the wall (as illustrated by the white oval) (b), and the cold traps with a collection vial $(\bigcirc)$ inside (c).

(a)

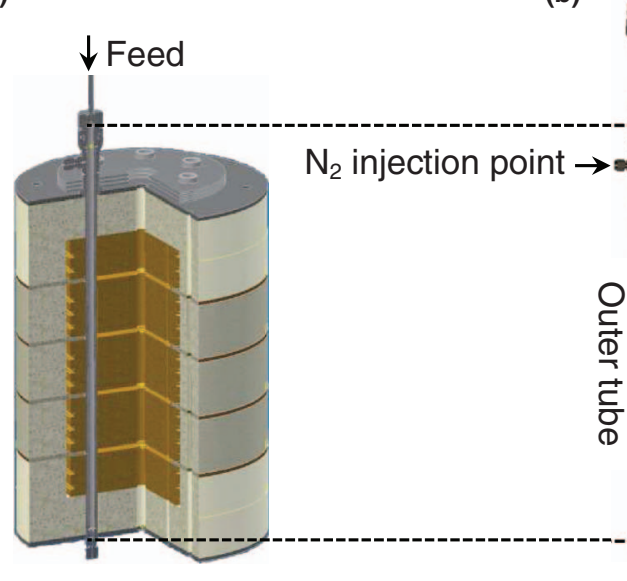

(b)

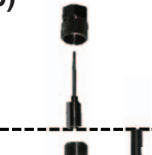



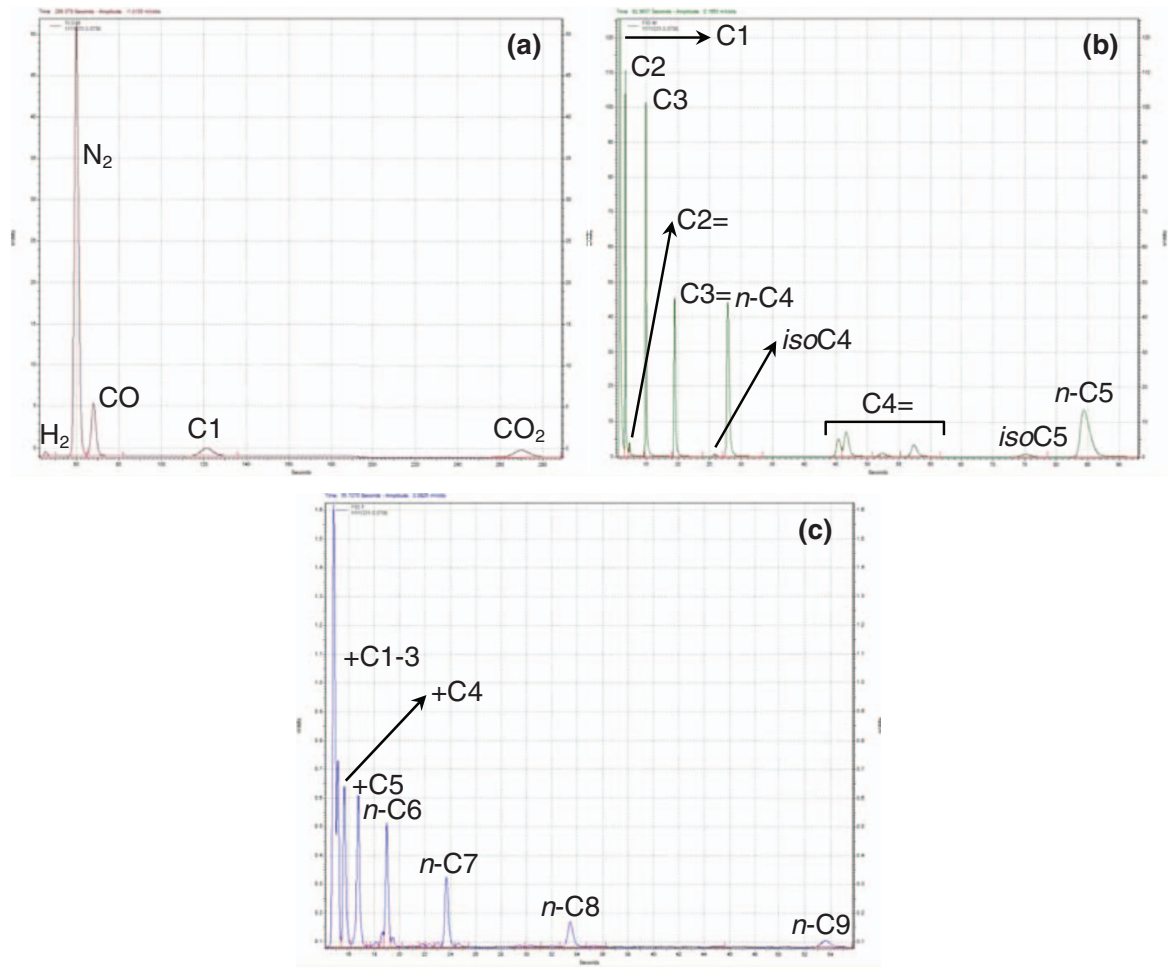

FIG. 6. Compact GC chromatograms of reactor effluents in the gas phase, analyzed on-line after $20 \mathrm{~h}$ on-stream over $10 \mathrm{wt} . \% \mathrm{Co} / \mathrm{SiO}_{2}$ at $533 \mathrm{~K}, 10 \mathrm{bar}$ total pressure, feed composition $\mathrm{H}_{2} / \mathrm{CO}=2$, and GHSV $=2.4 \mathrm{~m}^{3} \mathrm{STP} \mathrm{kg}^{-1}$ cat $^{-1}$. TCD signal (a) and FID signals (b) and (c). C2 =: ethylene, C3 =: propylene, isoC4: isobutane, iso C5: isopentane, $+\mathrm{C} 1-3$ : all $\mathrm{C} 1-\mathrm{C} 3$ hydrocarbons, $+\mathrm{C} 4$ : all $\mathrm{C} 4$ hydrocarbons, and $+\mathrm{C} 5$ : all $\mathrm{C} 5$ hydrocarbons.

occasionally to calibrate the MFCs or measure the gas flows (Figure 2). Most of the setup equipment is computer controlled through a dedicated LabVIEW code. Instrument models are reported in Table S1 in the supplementary material. ${ }^{17}$

\section{PRODUCT ANALYSIS AND QUANTIFICATION}

\section{A. Online analysis of gas phase reactor effluents}

The gas phase, containing light FTS hydrocarbons and unreacted feed, is analyzed online by a Compact GC from Interscience. The GC is equipped with three columns and detectors in parallel, using $\mathrm{He}$ as carrier gas. In the first column (Carboxen 1010, $10 \mathrm{~m} \times 0.32 \mathrm{~mm}$ ) $, \mathrm{H}_{2}, \mathrm{~N}_{2}, \mathrm{CO}$, $\mathrm{CH}_{4}$, and $\mathrm{CO}_{2}$ are separated at $333 \mathrm{~K}$ and analyzed by TCD (Figure 6(a)). In the second column $\left(\mathrm{Al}_{2} \mathrm{O}_{3} / \mathrm{KCl}, 10 \mathrm{~m}\right.$ $\times 0.32 \mathrm{~mm}$ ) and FID detection, separation between all $\mathrm{C} 1-$ $\mathrm{C} 4$ components is achieved at $434 \mathrm{~K}$ (Figure 6(b)). In the third column (RTx-1 $0.5 \mathrm{~lm}, 15 \mathrm{~m} \times 0.32 \mathrm{~mm}$ ), C5-C10 hydrocarbons are separated at $353 \mathrm{~K}$ and detected by FID (Figure 6(c)). The analysis duration for each sample is less than $5 \mathrm{~min}$.

Total flow rate of the reactor effluents in gas phase $\left(v_{\text {T,gas }}\right.$, not including $\mathrm{N}_{2}$ ) can be calculated from Eq. (1) if the $\mathrm{N}_{2}$ molar fraction $\left(y_{\mathrm{N} 2, \text { loop }}\right)$ is measured

$$
y_{\mathrm{N} 2 \text {, loop }}=\frac{v_{\mathrm{N} 2}}{v_{\mathrm{N} 2}+v_{\mathrm{T}, \text { gas }}} .
$$

It should be noted that $v_{\mathrm{T}, \mathrm{gas}}$ is not necessarily equal to the total flow rate out of the corresponding FBM, due to (partial) separation of reaction products in HTs and CTs. On the other hand, since $\mathrm{N}_{2}$ is an inert gas, its flow rate is equal to what was fed downstream of the reactors $\left(v_{\mathrm{N} 2}\right.$, see Sec. II B).

Response factors $(r f)$ of the analysis equipment for the different components are obtained upon calibration with a mixture that contains $\mathrm{H}_{2}, \mathrm{~N}_{2}, \mathrm{CO}, \mathrm{CH}_{4}$, and $\mathrm{CO}_{2}$ (detected by TCD, Figure 6(a)) as well as all the hydrocarbons shown in Figure 6(b) (detected by FID). For higher hydrocarbons, $r f$ of all hydrocarbons with $n$ carbon number $(\mathrm{C} n)$ may be assumed to be equal and calculated from Eq. $(2)^{18}$

$$
r f_{\mathrm{C} n}=\frac{n-1}{n} r f_{\mathrm{C} n-1} .
$$

Therefore, Eq. (3) will provide the flow rate of component $i$ in gas phase reactor effluents $\left(v_{i, \text { gas }}\right)$

$$
v_{i, \text { gas }}=y_{i, \text { gas }} \nu_{\mathrm{T}, \text { gas }}=y_{i, \text { loop }}\left(v_{\mathrm{T}, \text { gas }}+v_{\mathrm{N} 2}\right) \text {, }
$$

where $y_{i, l o o p}$ is the molar fraction of component $\mathrm{i}$ in the $\mathrm{N}_{2}$ diluted gas phase and is directly obtained from the GC analysis. $v_{\mathrm{i} \text {,gas }}$ can be converted into molar flow rate, assuming the ideal gas behavior.

\section{B. Offline analysis of the collected samples}

After separation from the aqueous phase, liquid hydrocarbons (collected in CTs, Figure 7(a)) as well as the wax (collected in HTs, Figure 7(b)) can be weighted and analyzed offline to identify the overall product spectrum. Certainly, various analytical methods may be applied in this case such as simulated distillation (SimDis) chromatography, PIONA analysis, two-dimensional chromatography, etc. In this report, a SimDis GC (Hewlett Packard 5890, Series II) is 

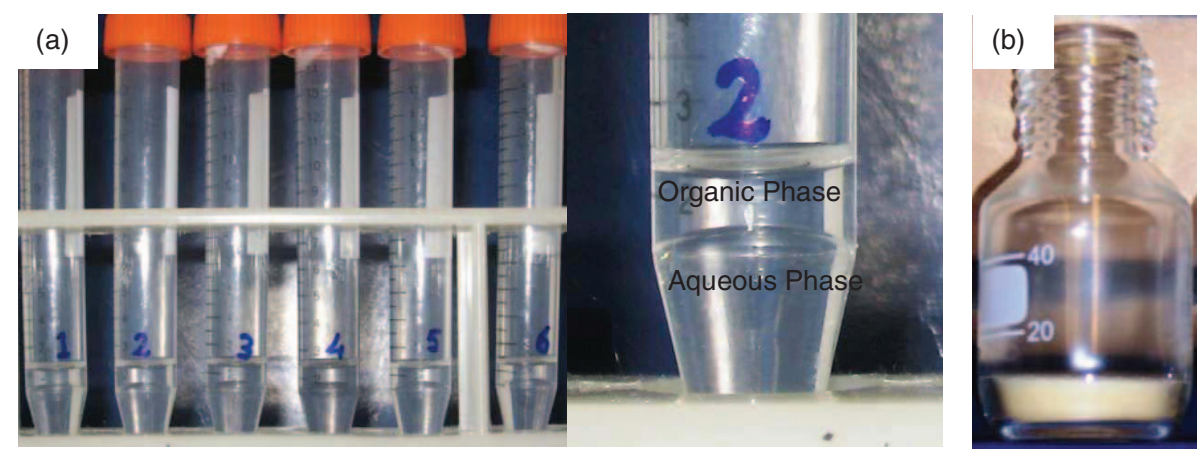

FIG. 7. Liquid FTS products (i.e., a biphasic mixture containing an organic phase over an aqueous phase), collected in the cold traps after $20 \mathrm{~h}$ on-stream at $533 \mathrm{~K}, 10$ bar total pressure, feed composition $\mathrm{H}_{2} / \mathrm{CO}=2$, and GHSV $=2.4 \mathrm{~m}^{3} \mathrm{sTP} \mathrm{kg}^{-1}$ cat $^{-1}$ (a). FBM 1-6 were loaded with the same catalyst batch of $10 \mathrm{wt} . \% \mathrm{Co} / \mathrm{SiO}_{2}$. FTS wax, separated in a hot trap and collected by the corresponding liquid collection vessel (b).

employed which is equipped with a FID and HP-1 column ( $7.5 \mathrm{~m} \times 0.53 \mathrm{~mm}$, film thickness $2.65 \mu \mathrm{m})$, using He as carrier gas. During the analysis, the oven temperature is ramped from 35 to $350 \mathrm{~K}\left(14 \mathrm{~K} \mathrm{~min}^{-1}\right)$ and kept at the final temperature for $5 \mathrm{~min}$. Before injection, samples are diluted with $\mathrm{CS}_{2}$.

A representative chromatogram of the organic phase (as indicated in Figure 7(a)) shows that it contains C5-C20 hydrocarbons (Figure 8). Comparison between Figure 6(c) and 8 reveals that some $\mathrm{C} 5+$ hydrocarbons are noticeably present in both gas and liquid phases. Therefore, offline measurements are necessary for analysis of $\mathrm{C} 5+$, when flow selection is done by EWSV 2 (operation mode (ii), see Sec. II C). At the same time, such integration of offline and online data may lead to overestimation (or underestimation) of the fractional molar distributions for hydrocarbons that are present in both gas and liquid phases. This is due to temperature fluctuations of the refrigerator (Figures 2 and 4(c)), which may result in a lower (or higher) average temperature of CTs during the collection period, as compared with their temperature at the instant of the online analysis. So to demonstrate, a flash separation of FTS product mixture (at $\alpha=0.9$ ) was simulated by Aspen Plus, employing the Peng-Robinson thermodynamic model. The simulation integrated the gas phase composition at different flash separation temperatures with that of the liquid phase for a flash separation at $273 \mathrm{~K}$. Figure 9 shows that such temperature variations lead to artifacts in the form of a "bump" in fractional molar distribution of FTS hydrocarbons above $\mathrm{C} 5$.

\section{CASE STUDY: ASSESSMENT OF SIX-FLOW OPERATION}

\section{A. Catalyst}

$\mathrm{Co} / \mathrm{SiO}_{2}$ FTS catalyst was prepared by incipient wetness impregnation in one step, using a Co nitrate aqueous solution. Spherical particles of $\mathrm{SiO}_{2}$ (CARiACT Q-10, Fuji Silysia Chemical Ltd.) were loaded with $10 \mathrm{wt}$ \% of Co in a rotating vessel. The impregnated sample was kept under rotation for $\sim 0.5 \mathrm{~h}$ at room temperature and, subsequently, at $323-333 \mathrm{~K}$ for more than $2 \mathrm{~h}$. The catalyst was then dried overnight at $393 \mathrm{~K}$ and calcination was followed at $673 \mathrm{~K}$ for $2 \mathrm{~h}$ in static air conditions.

Textural and chemical properties of $\mathrm{SiO}_{2}$ support and $\mathrm{Co} / \mathrm{SiO}_{2}$ catalyst are summarized in Table $\mathrm{S} 2$ in the supplementary material. ${ }^{17}$ The temperature-programmed reduction profile in $\mathrm{H}_{2}$ of $\mathrm{Co} / \mathrm{SiO}_{2}$ is presented in Figure $\mathrm{S} 3$ in the supplementary material. ${ }^{17}$

\section{B. Setup operation}

$0.5 \mathrm{~g}$ of fresh $\mathrm{Co} / \mathrm{SiO}_{2}$ (from the same catalyst batch) was fixed in the six reactor inserts, using quartz wool plugs.

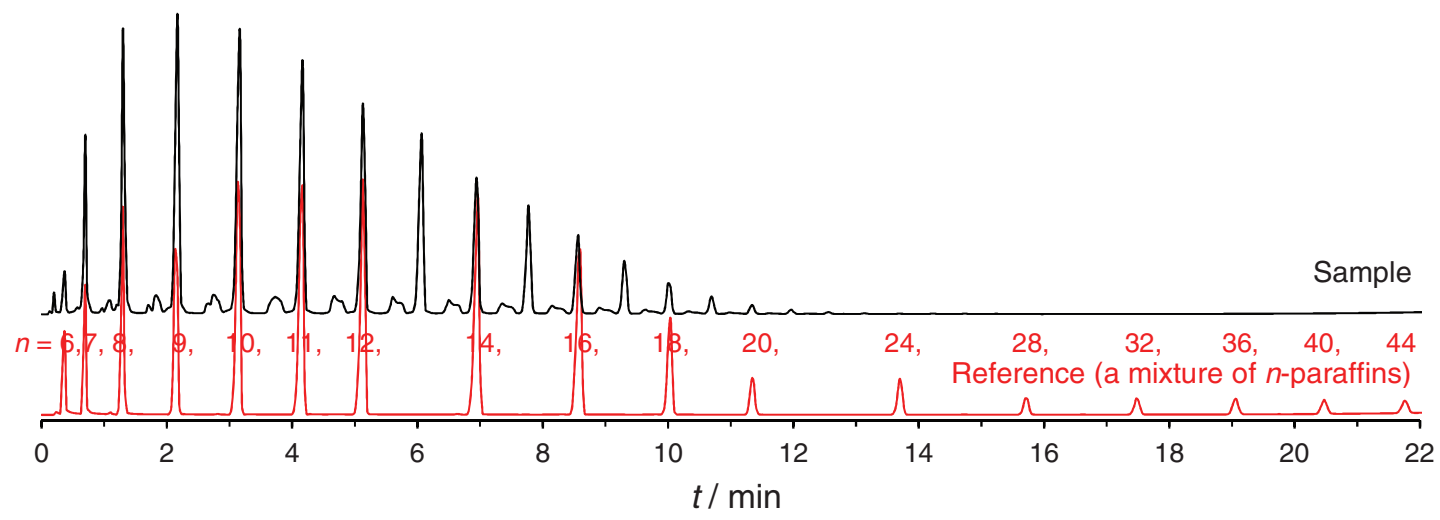

FIG. 8. SimDis GC chromatogram of liquid FTS hydrocarbons, collected after $20 \mathrm{~h}$ on-stream over $10 \mathrm{wt} \% \mathrm{Co} / \mathrm{SiO}_{2}$ at $533 \mathrm{~K}, 10 \mathrm{bar}$ total pressure, feed composition $\mathrm{H}_{2} / \mathrm{CO}=2$, and $\mathrm{GHSV}=2.4 \mathrm{~m}^{3} \mathrm{STP} \mathrm{kg}^{-1}$ cat $\mathrm{h}^{-1}$. $n$ : carbon number. 


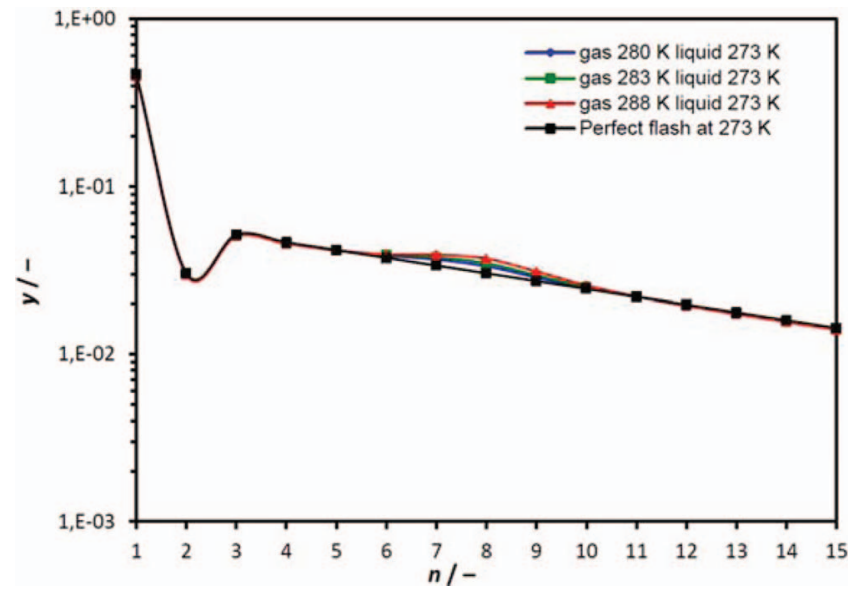

FIG. 9. Fractional molar distribution of FTS hydrocarbons $(\alpha=0.9)$ obtained after a flash separation of liquid and gas phases. Composition of the gas phase at different flash separation temperatures was integrated with that of the liquid phase for a flash separation at $273 \mathrm{~K}$.

Samples were first activated in situ by $80 \mathrm{~cm}^{3}$ STP $\min ^{-1}$ of $\mathrm{H}_{2}$ at $673 \mathrm{~K}$ for $12 \mathrm{~h}$ at atmospheric pressure followed by cooling down to $453 \mathrm{~K}$ under $\mathrm{H}_{2}$ flow. After setting the total feed flow rate to each reactor (by MFCs 5-10), the pressure was increased to the process value (10 or 15 bar total pressure) and $\mathrm{CO}$ was gradually introduced to the feed stream (via MFC 3) at $453 \mathrm{~K}$ in order to reach its final concentration $\left(5.0 \mu \mathrm{mol}_{\mathrm{CO}} \mathrm{s}^{-1}, \mathrm{H}_{2} / \mathrm{CO}=2\right)$ in $1 \mathrm{~h}$. Subsequently, the reactor system was heated to the process temperature ( 513 or $533 \mathrm{~K}$ ). A rate of $2 \mathrm{~K} \mathrm{~min}^{-1}$ was applied for all the heating/cooling steps. During the experiment at $513 \mathrm{~K}$, heavy hydrocarbons (wax) were collected by HTs at $448 \mathrm{~K}$ and reaction pressure. After expansion of the product flow to atmospheric pressure, lighter hydrocarbons and water were collected in CTs at $\sim 278 \mathrm{~K}$. Product analysis was done in operation mode (ii) as explained in Sec. II C and following the methodology described in Sec. III.

A pseudo-steady-state condition was attained after $20 \mathrm{~h}$ on-stream when the internal volume of the experimental setup was thoroughly flushed by the (liquid) reaction effluents and the decrease in CO conversion (with time) contracted (see Sec. IV C). CO conversion, carbon selectivity, and molar fraction of each product were defined by Eqs. (4)-(6), respectively, where $X_{\mathrm{CO}}$ stands for $\mathrm{CO}$ conversion (\%), $F$ indicates the molar flow rate, $S$ is the carbon selectivity (\%) toward a product with $n$ carbon atoms, and $y$ is the molar fraction of a hydrocarbon $\mathrm{C} n$

$$
\begin{gathered}
X_{\mathrm{CO}}=\frac{F_{\mathrm{in}, \mathrm{CO}}-F_{\mathrm{out}, \mathrm{CO}}}{F_{\mathrm{in}, \mathrm{CO}}} \times 100, \\
S_{\mathrm{C} n}=\frac{n F_{\mathrm{C} n}}{F_{\mathrm{CO}_{2}}+\sum_{n=1}^{N} n F_{\mathrm{C} n}} \times 100, \\
y_{\mathrm{C} n}=\frac{F_{\mathrm{C} n}}{\sum_{n=1}^{N} F_{\mathrm{C} n}} .
\end{gathered}
$$

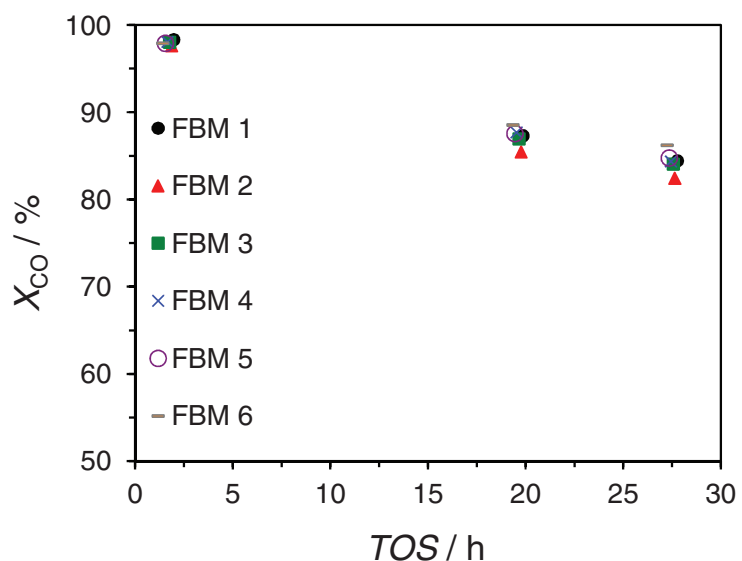

FIG. 10. Time-on-stream (TOS) evolution of the CO conversion during FTS at $533 \mathrm{~K}, 10$ bar total pressure, feed composition $\mathrm{H}_{2} / \mathrm{CO}=2$, and GHSV $=2.4 \mathrm{~m}^{3} \mathrm{STP} \mathrm{kg}^{-1}$ cat $^{-1}$. FBM 1-6 were loaded with the same catalyst batch of 10 wt. $\% \mathrm{Co} / \mathrm{SiO}_{2}$.

The $\alpha$ value was defined in terms of the rate of polymerization $\left(r_{\mathrm{p}}\right)$ and the rate of termination $\left(r_{\mathrm{t}}\right)$ of the growing hydrocarbons, according to Eq. (7)

$$
\alpha=r_{\mathrm{p}} /\left(r_{\mathrm{p}}+r_{\mathrm{t}}\right)
$$

Therefore, Eq. (8) represented the Anderson-SchulzFlory (ASF) product distribution in terms of molar fractions

$$
y_{\mathrm{C} n}=(1-\alpha) \alpha^{\mathrm{n}-1}
$$

and $\alpha$ value was calculated from the slope of $\ln \left(y_{\mathrm{C} n}\right)$ as a function of $n$ (i.e., expecting a first order function based of Eq. (8), the slope will be equal to $\ln (\alpha)$.)

\section{Results}

Time-on-stream (TOS) evolution of CO conversion in FBM 1-6 is depicted in Figure 10. 98\% conversion of CO is measured after $1-2 \mathrm{~h}$ of reaction. $\mathrm{CO}$ conversion decreases with TOS by $\sim 14 \%$ after $27 \mathrm{~h}$ on-stream. The maximum deviation from the average conversion value (between FBM 1-6) is $\pm 2 \%$, observed in case of FBM 2 and 6.

The collection period of liquid fraction (in CTs) was during 20-28 h TOS, when CO conversion decreases 3\% (Figure 10). Molar flow rates of liquid hydrocarbons, as averaged based on the collection duration and offline analysis, were added to their corresponding values obtained from the online analysis at $\sim 20 \mathrm{~h}$ TOS. The added flow rates were used to calculate the carbon selectivity (Eq. (5)) and molar fraction (Eq. (6)) of hydrocarbons that were present in more than one phase (see Sec. III B).

FBM 1-6 display very similar product selectivities (Figure 11(a)). Under the applied process conditions, the highest carbon selectivity is obtained for the $\mathrm{C} 5-\mathrm{C} 11$ fraction, while a minor amount of $\mathrm{C} 21+$ is formed over $\mathrm{Co} / \mathrm{SiO}_{2}$. The very low production of $\mathrm{C} 21+$ is observed in HTs as almost no wax sample could be collected for offline analysis. The olefin to paraffin ratio in $\mathrm{C} 2-\mathrm{C} 4$ fraction $(\mathrm{O} / \mathrm{P}(\mathrm{C} 2-4))$ is $\sim 0.4$ (inset in Figure 11(a)) which points to prevalence of saturated hydrocarbons throughout the product spectrum $(\mathrm{O} / \mathrm{P}$ 
(a)

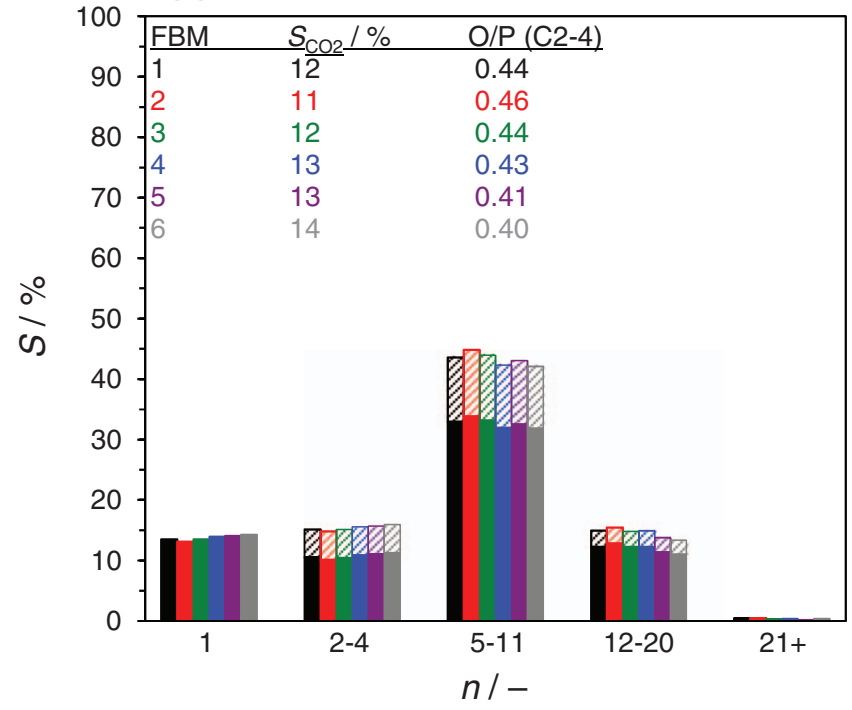

(b)

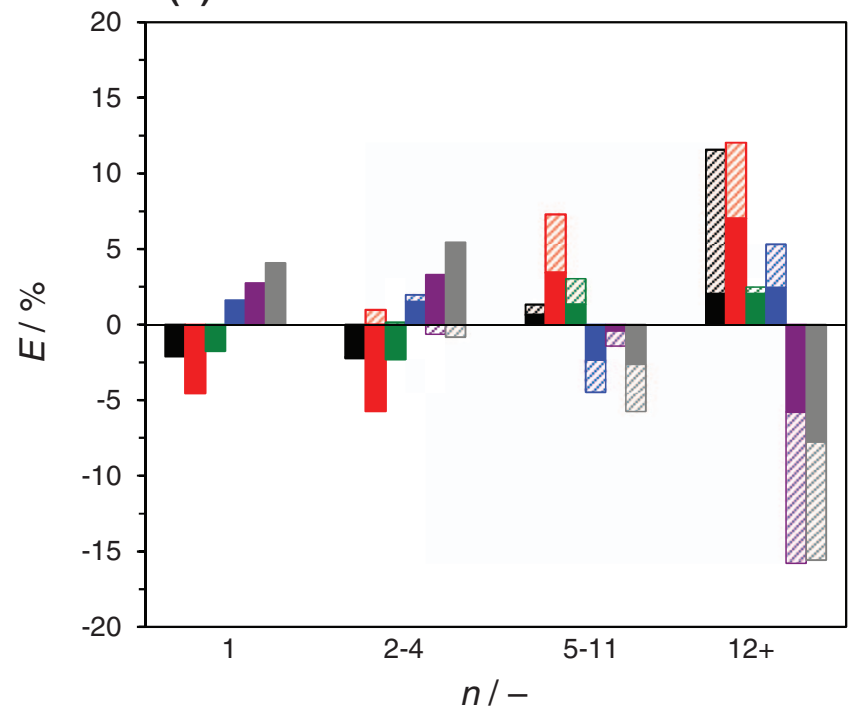

FIG. 11. Carbon selectivity of FTS products after $20 \mathrm{~h}$ on-stream (a). Relative errors associated with carbon selectivities to each product range with respect to the average value (between FBM 1-6) (b). In each carbon number group from left to right: FBM 1 to FBM 6. $\mathbf{a}$ : $n$-paraffins; $\mathbb{Z}$ : sum of isoparaffins and olefins; $S_{\mathrm{CO} 2}$ : $\mathrm{CO}_{2}$ selectivity; O/P $(\mathrm{C} 2-4)$ : olefin to paraffin ratio of $\mathrm{C} 2-\mathrm{C} 4$. Experiment was performed at $533 \mathrm{~K}, 10$ bar total pressure, feed composition $\mathrm{H}_{2} / \mathrm{CO}=2$, and $\mathrm{GHSV}=2.4 \mathrm{~m}^{3} \mathrm{STP} \mathrm{kg}^{-1}$ cat $\mathrm{h}^{-1}$. FBM 1-6 were loaded with the same catalyst batch of 10 wt. $\% \mathrm{Co} / \mathrm{SiO}_{2}$.

ratio decreases for larger hydrocarbons due to their stronger adsorption ${ }^{19}$ followed by hydrogenation). ${ }^{20}$ The $\mathrm{CO}_{2}$ selectivity is above $10 \%$ suggesting a considerable contribution of water-gas-shift (WGS) over the studied Co-catalyst at $533 \mathrm{~K}$.

Relative errors $(E)$ between reactors associated with carbon selectivities to each product range, with respect to the average value (between FBM 1-6, $S_{\mathrm{C} n \text {,average }}$ ) was calculated by Eq. (9) and is presented in Figure 11(b)

$$
E_{\mathrm{C} n}=\frac{S_{\mathrm{C} n}-S_{\mathrm{C} n, \text { average }}}{S_{\mathrm{C} n, \text { average }}} \times 100 .
$$

Note that for each group, the error associated with isoparaffins and olefins is separated from that related to $n$ - paraffins. $E$ is maximum $6 \%$ for hydrocarbon fractions up to $\mathrm{C} 11$ and $10 \%$ for $\mathrm{C} 12+$.

The molar fraction of FTS hydrocarbons versus their carbon number follow a fairly (log)linear trend up to C17 (Figure 12(a)). C1 and C2 are exceptions which show, respectively, higher and lower values than what is anticipated by extrapolating the linear distribution to $n=1$ and 2 . In order to assess the performance of the setup when working at a higher $\alpha$ values (cf. insets in Figures 12(a) and 12(b)), additional experiments were performed at lower temperature $(513 \mathrm{~K})$. Figure 12(b) shows that the linear trend continues for $n>17$.

\section{DISCUSSION}

The lab-scale six-flow FTS setup, introduced in this report, includes six fixed-bed microreactors of which feed flow rate and process pressure may be adjusted independently. Moreover, each flow is equipped with phase separators aiding an independent collection of solid and liquid samples. At the same time, the six-flow unit benefits from operation under similar feed composition, reaction and product separation temperatures, and conditions of the online analytical equipment (e.g., calibration, etc.). While the former independent parameters increase the experimentation throughput, the latter similarities will certainly improve its accuracy. Enhancements in both throughput and accuracy are the advantages of such a system over six independent units. The condition is that all the reactors (flows) should behave identical, i.e., provide similar results employing the same catalyst.

Testing the same batch of $\mathrm{Co} / \mathrm{SiO}_{2}$ catalyst in the six-flow setup confirms that the six FBMs operate almost identical in terms of activity and selectivity measurements. With respect to the average $\mathrm{CO}$ conversion, FBMs 2 and 6 show about $1 \%-$ $2 \%$ lower and higher values, respectively (Figure 10). Carbon selectivity to $\mathrm{C} 1-\mathrm{C} 4$ and $\mathrm{CO}_{2}$ are lowest in FBM 2 and highest in the case of FBM 6 (Figure 11). At the same time, selectivity to $\mathrm{C} 5+$ and $\mathrm{O} / \mathrm{P}(\mathrm{C} 2-4)$ are highest in FBM 2 and lowest for FBM 6. Slight fluctuations in local temperatures can potentially lead to such observation since Co-based FTS catalysts are very sensitive to changes in the process temperature in terms of their product selectivity. ${ }^{21}$ The construction of the six-flow FBM with five separate heating zones and very narrow reactor inserts results in an identical temperature profile in FBM 1-6 in absence of reaction (Figures 5(c) and S1 in the supplementary material ${ }^{17}$ ). On the other hand, all catalyst beds were carefully packed in the $10 \mathrm{~cm}$ isothermal region of FBM 1-6 by means of a dedicated rod followed by tapping. Therefore, the above-mentioned alterations cannot originate from the reactor oven temperature. Indeed, deviations in the obtained results are expected when catalytic measurements are duplicated (even with the same reactor). Variances such as those in packing the catalyst beds, inhomogeneity in a catalyst batch, etc., may significantly contribute to experimental errors in addition to other sources (e.g., analytical, mass and flow measurements, etc.). ${ }^{10}$ The FTS reaction is highly exothermic $^{22}$ and the aforementioned catalysts' performance results suggest that small differences in heat dissipation from 
(a)

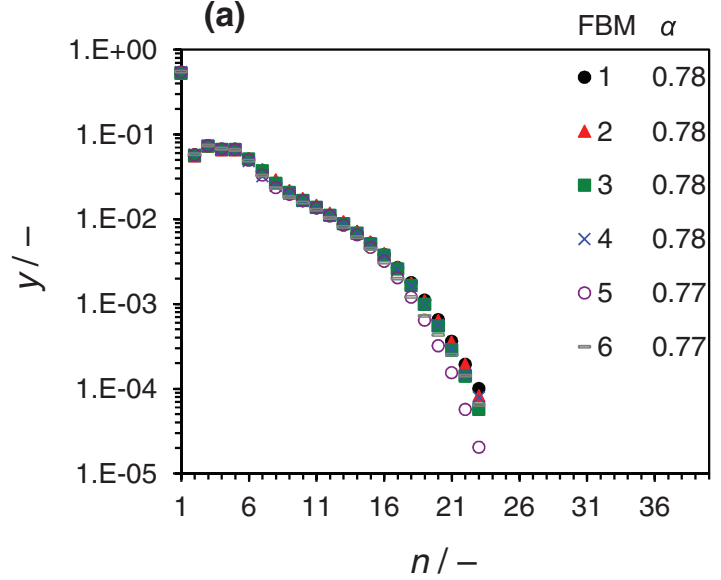

(b)

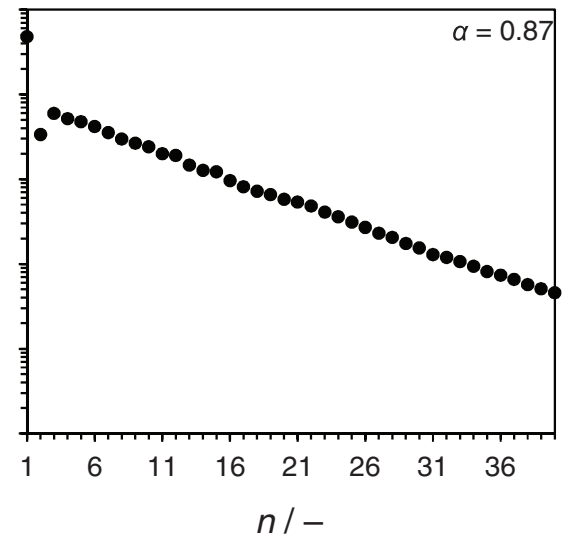

FIG. 12. Fractional molar composition of FTS hydrocarbons after $20 \mathrm{~h}$ on-stream over $\mathrm{Co} / \mathrm{SiO}_{2}$ at $533 \mathrm{~K}, 10 \mathrm{bar}$ total pressure (a) and $513 \mathrm{~K}$, 15 bar total pressure (b), feed composition $\mathrm{H}_{2} / \mathrm{CO}=2$, and GHSV $=2.4 \mathrm{~m}^{3} \mathrm{STP} \mathrm{kg}^{-1}$ cat $\mathrm{h}^{-1}$. In (a), FBM $1-6$ were loaded with the same catalyst batch. Chain growth probability $(\alpha)$ is calculated in the range of $\mathrm{C} 5-\mathrm{C} 16$

the catalyst beds and/or occurrence of hotspots may have an important role in this case.

The ASF distribution implies a log-linear trend for fractional molar composition of FTS hydrocarbons when plotted versus their carbon number. ${ }^{23}$ Although this assumption is fairly relevant for many catalytic systems, several reports deal with non-ASF product distributions. ${ }^{24}$ Dissimilar sites or (parallel) growth mechanisms in one catalyst, ${ }^{25}$ altered $\alpha$ values in different carbon number regions, ${ }^{26}$ and the so-called "bifunctional catalysts" that represent a "break" in ASF plot ${ }^{27}$ are among such exceptions. Moreover, the degree of saturation (and/or branching) may vary at different hydrocarbon ranges, even over an ASF-behaving catalyst. Thus, analysis of the whole product spectrum is of crucial importance in order to fully unveil the performance of a FTS catalyst. This asks for running reactions with a sufficient production of liquid and solid amounts in the case of studies dealing with gasto-liquid conversions (i.e., when high $\alpha$ values are aimed for). Excluding the heavies from the analysis may lead to artifacts in the form of deviation from ASF distribution (Figure 12(a)) and results in elevated errors in the selectivity data above $\mathrm{C} 11$ (Figure 11(b)).

If process conditions are fixed, productivity of a reaction can be increased by loading more catalyst in the reactor while keeping the space velocity constant. In this case, the necessary amount of sample may reach above a gram, since FTS catalysts in general are not highly productive. Conventional "one-flow" setups can easily be adopted for such amounts as they are less limited by space. However, upon numbering up the reactors (flows), a compromise should be made between the equipment volume (/capital), operation complexity, and extensive data acquisition. In this respect, a six-flow equipment in the lab-scale bridges the gap between highthroughput setups for primary screening of FTS catalysts and conventional one-flow systems for their detailed performance studies. As a show case, the current setup has been employed for studying a number of zeolite-containing Cocatalysts which are proven to combine FTS and acid catalyzed reactions. ${ }^{27-31}$ The product compositions of these catalysts above $\mathrm{C} 11$ cannot be described by an ASF distribution. ${ }^{27,30}$ Therefore, an almost extensive analysis of liquid products was essential (Figure S4 in the supplementary material ${ }^{17}$ ) in addition to a time efficient catalyst screening. This was offered by the operation mode (ii) (see Sec. II C) of the six-flow fixedbed microreactor FTS setup.

\section{CONCLUSIONS}

A relatively long catalyst stabilization period stresses the necessity of high-throughput experimentation in research areas related to FTS catalyst developments. As long as activity and selectivity measurements are concerned, lab-scale sixflow operations offer an increased experimental throughput as well as accuracy. The latter is due to equal conditions (in terms of process temperature, feed composition, equipment conditions, etc.) under which the six parallel experiments are performed and is ensured if the flows operate identically. Design, construction, and operation of such an equipment confirm that indeed it is possible to obtain reproducible activity and selectivity data within $6 \%$ relative error (with respect to the average value between the six flows). Our results suggest that minor differences in local temperatures may be the major basis of slight deviation from the average activity and selectivity values, in addition to other sources of experimental error.

Incorporation of separate mass and pressure controllers as well as product separation units in each flow allows running reactions with high production of solid and liquid fractions. Including these fractions in the product analysis (as in the case of conventional one-flow operations) is of great importance to fully characterize the FTS product spectra. Since the number of reactors is not as many as in high-throughput setups (bearing more than 10 flows) such instrumental considerations will not lead to a dramatic increase in the equipment volume (and as consequence, in the associated capital cost). Therefore, a six-flow fixed-bed microreactor unit combines 
the advantages of high-throughput and conventional FTS setups at lab-scale.

\section{APPENDIX: NOMENCLATURE}

$\begin{array}{ll}+\mathrm{C} 1-3 & \text { All C1-C3 hydrocarbons } \\ +\mathrm{C} 4 & \text { All C4 hydrocarbons } \\ +\mathrm{C} 5 & \text { All C5 hydrocarbons } \\ \alpha & \text { Chain growth probability } \\ v & \text { Volumetric flow rate } \\ \mathrm{C} 2 & \text { Ethylene } \\ \mathrm{C} 3 & \text { Propylene } \\ \mathrm{Cn} & \text { Hydrocarbon with } n \text { carbon number } \\ E & \text { Relative error } \\ F & \text { Molar flow rate } \\ i s o \mathrm{C} 4 & \text { Isobutane } \\ i s o \mathrm{C} 5 & \text { Isopentane } \\ l & \text { Length } \\ n & \text { Carbon number } \\ \mathrm{O} / \mathrm{P}(\mathrm{C} 2-4) & \text { Olefin to paraffin ratio in C2-C4 fraction } \\ r & \text { Rate } \\ r f & \text { Response factors } \\ S & \text { Carbon selectivity } \\ T & \text { Temperature } \\ t & \text { Time } \\ \text { TOS } & \text { Time-on-stream } \\ X & \text { Conversion } \\ y & \text { Molar fraction } \\ \text { gas } & \text { Gas phase } \\ \mathrm{i} & \text { Component index } \\ \text { loop } & \text { GC sample loop } \\ \mathrm{p} & \text { Polymerization } \\ \mathrm{T} & \text { Total } \\ \mathrm{t} & \text { Termination } \\ & \end{array}$

${ }^{1}$ L. Singoredjo, M. Slagt, J. van Wees, F. Kapteijn, and J. A. Moulijn, Catal. Today 7, 157 (1990).

${ }^{2}$ J. Pérez-Ramírez, R. J. Berger, G. Mul, F. Kapteijn, and J. A. Moulijn, Catal. Today 60, 93 (2000).

${ }^{3}$ F. Kapteijn and J. A. Moulijn, in Handbook of Heterogeneous Catalysis, edited by G. Ertl, H. Knözinger, F. Schüth, and J. Weitkamp (Wiley-VCH Verlag GmbH and Co. KGaA, Weinheim, 2008), pp. 2019-2045.

${ }^{4}$ H. W. Turner, A. F. Volpe, Jr., and W. H. Weinberg, Surf. Sci. 603, 1763 (2009).
${ }^{5}$ T. Zech, G. Bohner, O. Laus, J. Klein, and M. Fischer, Rev. Sci. Instrum. 76, 062215 (2005).

${ }^{6}$ D. A. Wood, C. Nwaoha, and B. F. Towler, J. Nat. Gas Sci. Eng. 9, 196 (2012).

${ }^{7}$ S. T. Sie, M. M. G. Senden, and H. M. H. van Wechem, Catal. Today 8, 371 (1991).

${ }^{8}$ A. de Klerk and E. Furimsky, Catalysis in the Refining of Fischer-Tropsch Syncrude (RSC Publishing, Cambridge, UK, 2010).

${ }^{9}$ N. E. Tsakoumis, M. Rønning, Ø. Borg, E. Rytter, and A. Holmen, Catal. Today 154, 162 (2010).

${ }^{10}$ J. A. Moulijn, J. Pérez-Ramírez, R. J. Berger, G. Hamminga, G. Mul, and F. Kapteijn, Catal. Today 81, 457 (2003).

${ }^{11}$ R. de Deugd, Ph.D. thesis, Delft University of Technology, Netherlands, 2004.

${ }^{12}$ A. Y. Khodakov, W. Chu, and P. Fongarland, Chem. Rev. 107, 1692 (2007).

${ }^{13}$ J. K. van der Waal, G. Klaus, M. Smit, and C. M. Lok, Catal. Today 171, 207 (2011).

${ }^{14}$ H. M. T. Galvis, J. H. Bitter, C. B. Khare, M. Ruitenbeek, A. I. Dugulan, and K. P. de Jong, Science 335, 835 (2012).

${ }^{15}$ H. M. Torres Galvis, J. H. Bitter, T. Davidian, M. Ruitenbeek, A. I. Dugulan, and K. P. de Jong, J. Am. Chem. Soc. 134, 16207 (2012).

${ }^{16}$ H. M. Torres Galvis, A. C. J. Koeken, J. H. Bitter, T. Davidian, M. Ruitenbeek, A. I. Dugulan, and K. P. de Jong, J. Catal. 303, 22 (2013).

${ }^{17}$ See supplementary material at http://dx.doi.org/10.1063/1.4834895 for equipment descriptions and models associated with Figures 2 and 3, catalyst characterization, and additional product chromatograms.

${ }^{18}$ J. L. Dierickx, P. M. Plehiers, and G. F. Froment, J. Chromatogr. A 362, 155 (1986).

${ }^{19}$ J. Wei, Ind. Eng. Chem. Res. 33, 2467 (1994).

${ }^{20}$ E. W. Kuipers, I. H. Vinkenburg, and H. Oosterbeek, J. Catal. 152, 137 (1995).

${ }^{21}$ H. Schulz, Stud. Surf. Sci. Catal. 163, 177 (2007).

${ }^{22}$ D. Vervloet, M. R. Kamali, J. J. J. Gillissen, J. Nijenhuis, H. E. A. van den Akker, F. Kapteijn, and J. R. van Ommen, Catal. Today 147, S138 (2009).

${ }^{23}$ C. G. Visconti, E. Tronconi, L. Lietti, P. Forzatti, S. Rossini, and R. Zennaro, Top. Catal. 54, 786 (2011).

${ }^{24}$ E. W. Kuipers, C. Scheper, J. H. Wilson, I. H. Vinkenburg, and H. Oosterbeek, J. Catal. 158, 288 (1996).

${ }^{25}$ M. Claeys and E. van Steen, Stud. Surf. Sci. Catal. 152, 601 (2004).

${ }^{26}$ K. D. Kruit, D. Vervloet, F. Kapteijn, and J. R. van Ommen, Catal. Sci. Technol. 3, 2210 (2013)

${ }^{27}$ S. Sartipi, K. Parashar, M. Makkee, J. Gascon, and F. Kapteijn, Catal. Sci. Technol. 3, 572 (2013).

${ }^{28}$ S. Sartipi, M. Alberts, M. J. Meijerink, T. C. Keller, J. Pérez-Ramírez, J. Gascon, and F. Kapteijn, ChemSusChem 6, 1646 (2013).

${ }^{29}$ S. Sartipi, M. Alberts, V. P. Santos, M. Nasalevich, J. Gascon, and F. Kapteijn, "Insights into the catalytic performance of mesoporous H-ZSM5-supported cobalt in Fischer-Tropsch synthesis," Chem. Cat. Chem (in press).

${ }^{30}$ S. Sartipi, K. Parashar, M. J. Valero-Romero, V. P. Santos, B. van der Linden, M. Makkee, F. Kapteijn, and J. Gascon, J. Catal. 305, 179 (2013).

${ }^{31}$ S. Sartipi, J. van Dijk, J. Gascon, and F. Kapteijn, Appl. Catal., A 456, 11 (2013) 